Check for updates

Cite this: RSC Adv., 2017, 7, 19954

Received 20th February 2017 Accepted 29th March 2017

DOI: 10.1039/c7ra02102j

rsc.li/rsc-advances

\section{The relative length of dual-target conjugated on iron oxide nanoparticles plays a role in brain glioma targeting $\dagger$}

\author{
Penghui Ai,,$^{a}$ Hao Wang, $\dot{t}^{c}$ Kang Liu, ${ }^{b}$ Tingjian Wang, ${ }^{a}$ Wei Gu, ${ }^{b}$ Ling Ye $\mathbb{D}$ *b \\ and Changxiang Yan*a
}

\begin{abstract}
The application of superparamagnetic iron oxide nanoparticles as a magnetic resonance (MR) nanoprobe for brain glioma is limited by the insufficient specificity and accumulation at the tumor site. To increase brain glioma-targeting specificity and improve MR contrast effect, dual-target has been employed. However, up to now, little work has been done to ascertain if the relative length of the dual-target plays a role in targeting. Herein, we prepared $\mathrm{Cy} 5.5$-labeled $\mathrm{Fe}_{3} \mathrm{O}_{4} \mathrm{NPs}$ with chlorotoxin (CTX)/PEGylated folic acid (PEG-FA) dual-target of different relative lengths. The effect of dual-target relative length on targeting specificity was investigated by in vitro cellular uptake and in vivo MR/NIR imaging in brain glioma-bearing mice. It was demonstrated that the targeting ability of the dual-targeting $\mathrm{Fe}_{3} \mathrm{O}_{4} \mathrm{NPs}$ could be modulated by adjusting the relative length of dual-target, suggesting that the relative length of dual-target plays a role in brain glioma targeting.
\end{abstract}

\section{Introduction}

Iron oxide nanoparticles (NPs) such as $\mathrm{Fe}_{3} \mathrm{O}_{4}$ NPs have been intensively investigated for their potential as $T_{2}$-weighted magnetic resonance (MR) imaging contrast agents owing to their intrinsic superparamagnetic properties and excellent biocompatibility. ${ }^{1-4}$ Several $\mathrm{Fe}_{3} \mathrm{O}_{4}$ NPs formulations are in experimental study stages or clinical trials..$^{5-8}$ However, there are few reports of successful application of $\mathrm{Fe}_{3} \mathrm{O}_{4}$ NPs for MR imaging of glioma due to the relatively low contrast enhancement caused by poor NPs uptake in brain tumors. Conjugation of specific moieties to the surface of $\mathrm{Fe}_{3} \mathrm{O}_{4}$ NPs can increase their uptake, thereby enhancing image resolution at target sites. For example, $\mathrm{Fe}_{3} \mathrm{O}_{4}$ NPs conjugated with single target, such as monoclonal antibodies (mAb), transferrin (Tf), lactoferrin, cyclic arginine-glycine-aspartic acid (cRGD), chlorotoxin (CTX) and folic acid (FA) have been shown to increase sensitivity when imaging brain tumors. ${ }^{9-16}$

Nonetheless, receptor saturation may limit the targeting efficiency of single-targeting NPs. ${ }^{17,18}$ On the other hand, most

\footnotetext{
${ }^{a}$ Department of Neurosurgery, Beijing Sanbo Brain Hospital, Capital Medical University, Beijing 100093, P. R. China. E-mail: yancx65828@sina.com

${ }^{b}$ School of Pharmaceutical Sciences, Capital Medical University, Beijing 100069, P. R. China. E-mail: lingye@ccmu.edu.cn

'Department of Anatomy, School of Basic Medical Sciences, Capital Medical University, Beijing 100069, P. R. China

$\dagger$ Electronic supplementary information (ESI) available. See DOI: $10.1039 / \mathrm{c} 7 \mathrm{ra02102j}$

$\ddagger$ These authors contributed equally to this work.
}

commonly targeted receptors are also expressed on some normal cells, which might cause unintended uptake in these off-target cells. ${ }^{19}$ Given that different types of receptor are overexpressed on the tumor cell surface, attaching multipletargeting moieties to the particle surface is expected to enhance tumor targeting. Various combinations of dual-targets including FA/mAb225, angiopep-2 peptides/cRGD, Tf/wheat germ agglutinin, FA/RGD, and Tf/RGD have been developed to improved tumor targeting specificity. ${ }^{\mathbf{2 0 , 2 1}}$

It has been theoretically suggested that interaction of dualtarget with receptors on the target cell surface is through concurrent binding. ${ }^{22}$ Therefore, it is rational that the relative length of the dual-target attaching on the surface of NPs may have an important effect on the targeting efficiency and consequently, the MR imaging quality of brain gliomas. However, up to now, little work has been done to ascertain if the relative length of the dual-target plays a role in tumor targeting.

In this study, we prepared near-infrared (NIR) dye Cy5.5labeled, glioma-targeting $\mathrm{Fe}_{3} \mathrm{O}_{4}$ NPs with CTX and PEGylated FA(PEG-FA) dual-target to improve targeting specificity of brain gliomas and MR imaging contrast effect. FA binds to folate receptor (FR) overexpressed by glioma cells with a high affinity, ${ }^{23}$ while CTX has high affinity for membrane-bound matrix metalloproteinase (MMP-2) specifically overexpressed by glioma and medulloblastoma cells. ${ }^{24}$ The targeting specificity of NPs with single- and dual-target was compared. Moreover, by modulating the length of PEG (2-5k range) for conjugation of FA, the effect of relative length on targeting specificity was investigated based on in vitro cellular uptake of C6 glioma cells and by in vivo MR/NIR imaging of glioma-bearing mice. 


\section{Experimental}

\subsection{Materials}

Bi-functional polyethylene glycol $\left(\mathrm{H}_{2} \mathrm{~N}-\mathrm{PEG}_{2 \mathrm{k}}-\mathrm{COOH}\right)$ and PEGylated folic acid (FA) with varied PEG chain length (FA$\mathrm{PEG}_{2 \mathrm{k}}-\mathrm{NH}_{2}$, FA-PEG $3.5 \mathrm{k}-\mathrm{NH}_{2}, \quad$ FA-PEG ${ }_{5 \mathrm{k}}-\mathrm{NH}_{2}$ ) were obtained from JenKem Technology Co. Ltd. (Beijing, China). CTX were obtained by GL Biochem Ltd. (Shanghai, China). Iron acetylacetonate $\left(\mathrm{Fe}(\mathrm{acac})_{3}\right)$, benzyl ether, oleylamine, and 1,2-hexadecanediol were purchased from Sigma-Aldrich (USA). $N$ (Trimethoxysilylpropyl)ethylene diamine triacetic acid, trisodium salt (TETT, $45 \%$ in water) was supplied by Gelest Inc (Morrisville, USA). Other chemical reagents with analytical grade were used directly without further purification.

\subsection{Synthesis of Cy5.5-labeled, dual-targeting $\mathrm{Fe}_{3} \mathrm{O}_{4} \mathrm{NPs}$}

Non-targeting, single-targeting, and dual-targeting $\mathrm{Fe}_{3} \mathrm{O}_{4}$ NPs labeled with Cy5.5 were fabricated based on the same parent batch of $\mathrm{Fe}_{3} \mathrm{O}_{4}$-TETT NPs, which were prepared according to our previously reported method without modifications. ${ }^{\mathbf{1 6}}$ Briefly, $100 \mathrm{mg}$ of $\mathrm{Fe}_{3} \mathrm{O}_{4}-\mathrm{TETT}$, Cy5.5- $\mathrm{PEG}_{2 \mathrm{k}}-\mathrm{NH}_{2}$ (synthesized by reacting of Cy5.5-NHS with $\mathrm{H}_{2} \mathrm{~N}-\mathrm{PEG}_{2 \mathrm{k}}-\mathrm{NH}_{2}$ at a molar ratio of 1 : 4 under $\mathrm{pH} 8.0$ ), and $100 \mathrm{mg}$ of $\mathrm{H}_{2} \mathrm{~N}-\mathrm{PEG}_{2 \mathrm{k}}-\mathrm{COOH}$ were mixed and stirred for $12 \mathrm{~h}$ to obtain the non-targeting Cy5.5labeled $\mathrm{Fe}_{3} \mathrm{O}_{4}$ NPs. Then, the carboxyl groups on the surface of $\mathrm{Fe}_{3} \mathrm{O}_{4}$ NPs $(100 \mathrm{mg})$ were activated with EDC and NHS and reacted with $3 \mathrm{mg}(0.75 \mu \mathrm{M})$ of CTX or $11 \mathrm{mg}(5.5 \mu \mathrm{M})$ of FA$\mathrm{PEG}_{2 \mathrm{k}}-\mathrm{NH}_{2}$ to obtain single-targeting $\mathrm{Fe}_{3} \mathrm{O}_{4}$ NPs $\left(\mathrm{Fe}_{3} \mathrm{O}_{4}-\mathrm{CTX}\right.$ and $\mathrm{Fe}_{3} \mathrm{O}_{4}$-PEG-FA). Meanwhile, another $100 \mathrm{mg}$ of activated $\mathrm{Fe}_{3} \mathrm{O}_{4}-\mathrm{PEG}_{2 \mathrm{k}}-\mathrm{Cy} 5.5$ were reacted with CTX/FA-PEG-NH $\mathrm{N}_{2}$ at a molar ratio of 1 : 7.3 to obtain dual-targeting $\mathrm{Fe}_{3} \mathrm{O}_{4}$ NPs with varied relative lengths $\left(\mathrm{Fe}_{3} \mathrm{O}_{4}-\mathrm{CTX} / \mathrm{PEG}_{2 \mathrm{k}}-\mathrm{FA}, \mathrm{Fe}_{3} \mathrm{O}_{4}-\mathrm{CTX} /\right.$ $\mathrm{PEG}_{3.5 \mathrm{k}}-\mathrm{FA}$, and $\left.\mathrm{Fe}_{3} \mathrm{O}_{4}-\mathrm{CTX} / \mathrm{PEG}_{5 \mathrm{k}}-\mathrm{FA}\right)$.

\subsection{Characterization}

Transmission electron microscopy (TEM) images of NPs were obtained on a JEM-2100F (JEOL, Tokyo, Japan) microscope operated at $120 \mathrm{kV}$. The magnetism of NPs was determined by a superconducting quantum interference device (SQUID, MPMSXL-7, Quantum Design, USA). The content of Fe was acquired on an inductively coupled plasma optical emission spectrometry (ICP-OES, Varian 710-ES, USA). The DLS measurements were conducted on a Nano-ZS90 Zetasizer (Malvern, UK). Ultraviolet-visible (UV-Vis) absorbance spectra were obtained with a UV-2600 spectrophotometer (Shimadzu, Japan). Fluorescence emission spectra were recorded on an F2500 fluorescence spectrophotometer (Hitachi, Japan).

The transverse relaxation times and corresponding $\mathrm{MR} T_{2}$ mappings of NPs were acquired on a 7T MR scanner (Bruker Pharmascan, Germany) with the RARE- $T_{1}+T_{2}$-map sequence. The parameters were set up in the following way: repetition times $(\mathrm{TR})=5000 \mathrm{~ms}, 3000 \mathrm{~ms}, 1500 \mathrm{~ms}, 800 \mathrm{~ms}, 400 \mathrm{~ms}$, multiple echo time $(\mathrm{TE})=11 \mathrm{~ms}, 33 \mathrm{~ms}, 55 \mathrm{~ms}, 77 \mathrm{~ms}, 99 \mathrm{~ms}$, matrix size $=256 \mathrm{~mm} \times 256 \mathrm{~mm}$, field of view $(\mathrm{FOV})=4.0 \times 4.0$ $\mathrm{cm}^{2}$, flip angle $(\mathrm{FA})=180^{\circ}$ and slice thickness $=1 \mathrm{~mm}$.

\subsection{Cytotoxicity}

C6 glioma cells were seeded in a 96-well plate. After $24 \mathrm{~h}$ incubation with NPs, CCK-8 solution $\left(100 \mu \mathrm{L}, 0.1 \mathrm{mg} \mathrm{mL}^{-1}\right)$ was supplemented to each well. The optical density (OD) value was examined on an enzyme-linked immunosorbent assay plate reader under $570 \mathrm{~nm}$ wavelength (Thermo Electron Corporation, USA). The cell viability was assessed by the ratio of OD values between the experimental group and the control group.

\subsection{In vitro cellular uptake and receptor blocking experiments}

C6 glioma cells were seeded in a 6-well plate. After $24 \mathrm{~h}$ incubation with NPs, C6 cells were treated with trypsin, washed with PBS, centrifuged, and resuspended in PBS. Uptake of NPs by C6 cells was analyzed by measuring the fluorescence intensity on a flow cytometer (Cyan-LX, DakoCytomation). The mean fluorescence intensity was determined by counting 10000 events ( $\lambda_{\mathrm{ex}}=488 \mathrm{~nm}, 680 / 40 \mathrm{~nm}$ bandpass filter). In receptor blocking experiment, excess CTX, PEG-FA, or CTX/PEG-FA were incubated with $\mathrm{C} 6$ glioma cells for $30 \mathrm{~min}$ prior to the addition of corresponding NPs. As a control, the cells without receptors blocking were incubated with the NPs as well. After incubation for $24 \mathrm{~h}$, flow cytometer measurements were conducted.

\subsection{In vivo MR and NIR imaging}

All animal experiments were in accordance with the National Institute of Health Guide for Care and Use of Laboratory Animals (publication no. 85-23, revised 1985) and the protocol approved by the ethical committee of Capital Medical University (Beijing, China). Mice brain glioma model was established based on the methodology described in the publication. ${ }^{25}$

In vivo $T_{2}$-weighted MR imaging experiments were performed on a 7T MRI scanner (Bruker Pharmascan, Germany). C6 glioma-bearing mice were injected with NPs by tail vein at $10 \mathrm{mg}$ Fe per $\mathrm{kg}$ body. The $T_{2}$-weighted $\mathrm{MR}$ images were obtained using the RARE sequence: $\mathrm{TR} / \mathrm{TE}=3000 / 45 \mathrm{~ms}$, matrix size $=$ $256 \mathrm{~mm} \times 256 \mathrm{~mm}$, field of view $=2.5 \times 2.5 \mathrm{~cm}^{2}$, flip angle $=$ $180^{\circ}$, slice thickness $=1 \mathrm{~mm}$ and number of averages $=4$. NIR imaging experiments were carried out on a NightOwl LB 983 in vivo imaging system (Berthold, Germany) equipped with a $630 \mathrm{~nm}$ excitation filter and a $680 \mathrm{~nm}$ emission band-pass filter set.

\subsection{Confocal laser microscopy imaging}

After MR/NIR imaging, the mice were anesthetized and perfused with physiological saline and 4\% paraformaldehyde. Then, the brains were harvested and fixed in $4 \%$ paraformaldehyde overnight and dehydrated with 30\% sucrose solution until subsidence. The excised brains were embedded in optimum cutting temperature compound (OCT) and frozen in liquid nitrogen for several seconds, sectioned at $20 \mu \mathrm{m}$ in thickness. Slides were examined under a confocal microscope with a $630 \mathrm{~nm}$ excitation filter and a $680 \mathrm{~nm}$ emission bandpass filter. 


\subsection{Biodistribution}

The glioma-bearing mice ( $n=3$ for each group) were injected intravenously with $0.2 \mathrm{~mL}$ of NPs (10 $\mathrm{mg}$ Fe per $\mathrm{kg}$ body). The mice were sacrificed at $24 \mathrm{~h}$ post-injection, and the brain, heart, liver, spleen, kidneys, and lungs were harvested, weighted and digested by the mixture of $30 \%$ hydrogen peroxide solution and nitric acid using a microwave digests system (CEM, Mars 5, USA). The contents of Fe in major organs were then determined by ICP-OES. As a control, the contents of Fe in major organs without injection of NPs were determined as well.

\section{Results and discussion}

\subsection{Synthesis and characterization}

Oleate (OA) stabilized $\mathrm{Fe}_{3} \mathrm{O}_{4}$ NPs were prepared by thermal decomposition of tris(acetylacetonato) iron(III) to obtain uniform size and high crystallinity. The capped OA was replaced with carboxylic TETT silane, yielding highly water-dispersible $\mathrm{Fe}_{3} \mathrm{O}_{4}$ NPs. PEG-Cy5.5 was conjugated to the surface of $\mathrm{Fe}_{3} \mathrm{O}_{4}-$ TETT NPs to render additional NIR imaging modality. Singletargeting NPs were obtained by attaching CTX or FA-PEG to non-targeting $\mathrm{Fe}_{3} \mathrm{O}_{4}$ NPs. Meanwhile, simultaneous conjugation of CTX and PEG-FA with varied PEG lengths to Cy5.5labeled, non-targeting NPs yielded dual-targeting $\mathrm{Fe}_{3} \mathrm{O}_{4}$ NPS with different relative lengths of dual-target $\left(\mathrm{Fe}_{3} \mathrm{O}_{4}-\mathrm{CTX} / \mathrm{PEG}_{2 \mathrm{k}^{-}}\right.$ FA, $\quad \mathrm{Fe}_{3} \mathrm{O}_{4}-\mathrm{CTX} / \mathrm{PEG}_{3.5 \mathrm{k}}-\mathrm{FA}$, and $\left.\mathrm{Fe}_{3} \mathrm{O}_{4}-\mathrm{CTX} / \mathrm{PEG}_{5 \mathrm{k}}-\mathrm{FA}\right)$ (Scheme 1). The FA and CTX were employed as dual-target because FA binds to FR overexpressed by glioma cells with a high affinity while CTX has high affinity for MMP-2 specifically overexpressed by glioma and medulloblastoma cells. Moreover, compared to Tf, mAb225, and angiopep-2 peptides, etc., the FA/ CTX has less steric hindrance. Meanwhile, inflammatory reaction induced by immune rejection could be avoided.
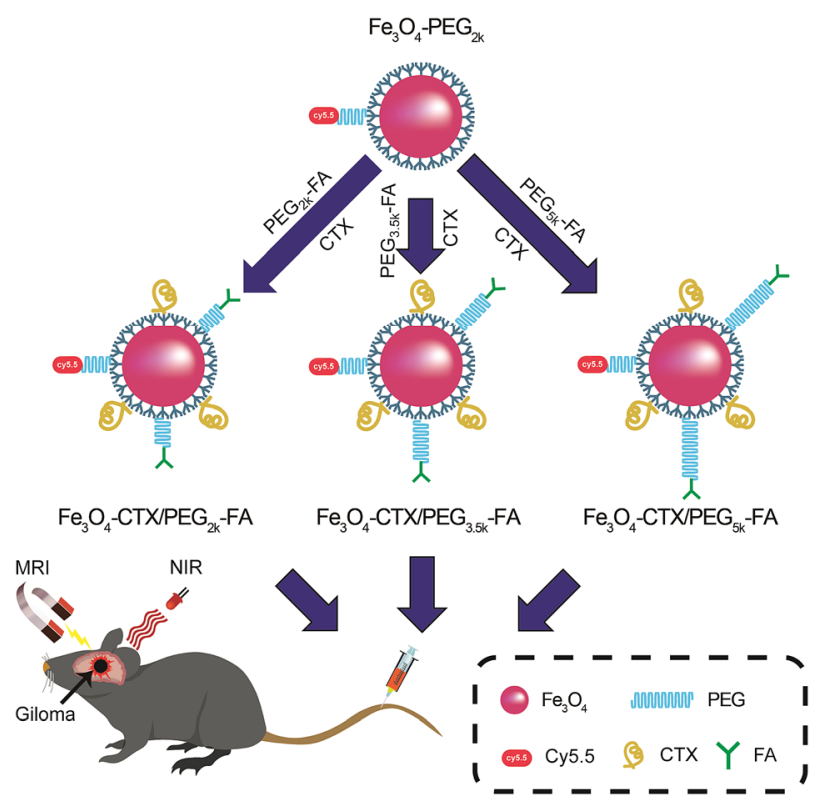

Scheme 1 Cy5.5-labeled $\mathrm{Fe}_{3} \mathrm{O}_{4}$ NPs with CTX/PEG-FA dual-target of varied relative lengths for MR/NIR imaging of brain glioma in mice.
Fig. 1(a)-(e) displays the TEM micrographs of singletargeting and dual-targeting $\mathrm{Fe}_{3} \mathrm{O}_{4}$ NPs. It was revealed that the attachment of single-target or dual-target onto $\mathrm{Fe}_{3} \mathrm{O}_{4} \mathrm{NPs}$ led to no significant changes in the shape as compared to that of non-targeting $\mathrm{Fe}_{3} \mathrm{O}_{4}$ NPs (Fig. S1 $\dagger$ ). However, the hydrodynamic size of single-targeting and dual-targeting $\mathrm{Fe}_{3} \mathrm{O}_{4}$ NPs (Fig. 1f) increased, indicating some extent of aggregation. Nevertheless, these single-targeting and dual-targeting $\mathrm{Fe}_{3} \mathrm{O}_{4}$ NPs remained highly stable in water for at least 2 week.

The conjugation of dual-target to $\mathrm{Fe}_{3} \mathrm{O}_{4}$ NPs was verified by UV-Vis absorbance spectrometry. The UV-Vis spectra of CTX and PEG-FA showed characteristic absorption peaks of CTX and PEG-FA at 278 and $282 \mathrm{~nm}$, respectively (Fig. 2a). The characteristic peaks of FA-PEG and CTX were observed in the UV-Vis spectra of $\mathrm{Fe}_{3} \mathrm{O}_{4}$-PEG-FA and $\mathrm{Fe}_{3} \mathrm{O}_{4}-\mathrm{CTX}$, respectively; these were concurrently presented in the UV-Vis spectra of dualtargeting $\mathrm{Fe}_{3} \mathrm{O}_{4}$ NPs, demonstrating the successful conjugation of dual-target. Meanwhile, the presence of the NIR fluorescence dye Cy5.5 was confirmed by the peak at $660 \mathrm{~nm}$ in the $\mathrm{UV}$-Vis spectrum and the emission peak at $700 \mathrm{~nm}$ in the fluorescence emission spectrum (Fig. 2b).

The magnetization of $\mathrm{Fe}_{3} \mathrm{O}_{4}$ NPs, which can affect $T_{2}$ relaxivity, was examined with a SQUID. No coercivity or remanence was observed at $300 \mathrm{~K}$ (Fig. S2 $\dagger$ ), providing evidence for the superparamagnetism of $\mathrm{Fe}_{3} \mathrm{O}_{4} \mathrm{NPs}$ at room temperature. The $M-H$ curve revealed that the saturated magnetization of $\mathrm{Fe}_{3} \mathrm{O}_{4}-$ OA NPs was $85.5 \mathrm{emu} \mathrm{g}^{-1}$ at $300 \mathrm{~K}$, which is comparable to the previously reported value. ${ }^{26}$

$\mathrm{Fe}_{3} \mathrm{O}_{4}$ NPs contrast agents usually shorten $T_{2}$ (spin-spin) relaxation times and result in darkening of the corresponding area in $T_{2}$-weighted MR images. The degree of the $T_{2}$ contrast effect is expressed as $r_{2}$, which represents the reciprocal of the relaxation time per unit concentration of magnetic ions. ${ }^{27}$ The $r_{2}$ value was calculated based on the gradient of $R_{2}\left(1 / T_{2}\right) v s$. the concentration of Fe ions (determined by ICP-OES). It was found $r_{2}$ values for dual-targeting NPs decreased slightly compared to those of non-targeting and single-targeting $\mathrm{Fe}_{3} \mathrm{O}_{4}$ NPs (Fig. 2c). This may be attributable to the dual-targeting CTX/PEG-FA on the NP surface, which impeded the contact of water molecules with $\mathrm{Fe}_{3} \mathrm{O}_{4}$ NPs. Nevertheless, these $r_{2}$ values were comparable

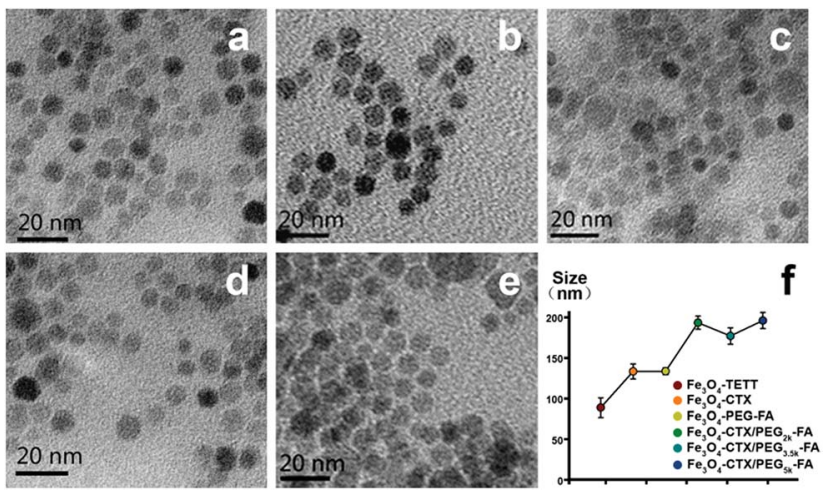

Fig. 1 TEM images of $\mathrm{Fe}_{3} \mathrm{O}_{4}-\mathrm{CTX}(\mathrm{a}), \mathrm{Fe}_{3} \mathrm{O}_{4}-\mathrm{PEG}-\mathrm{FA}$ (b), $\mathrm{Fe}_{3} \mathrm{O}_{4}-\mathrm{CTX} /$ $\mathrm{PEG}_{2 \mathrm{k}}-\mathrm{FA}$ (c), $\mathrm{Fe}_{3} \mathrm{O}_{4}-\mathrm{CTX} / \mathrm{PEG}_{3.5 \mathrm{k}}-\mathrm{FA}$ (d), and $\mathrm{Fe}_{3} \mathrm{O}_{4}-\mathrm{CTX} / \mathrm{PEG}_{5 \mathrm{k}}-\mathrm{FA}$ (e) NPs, and their DLS sizes (f). 
a
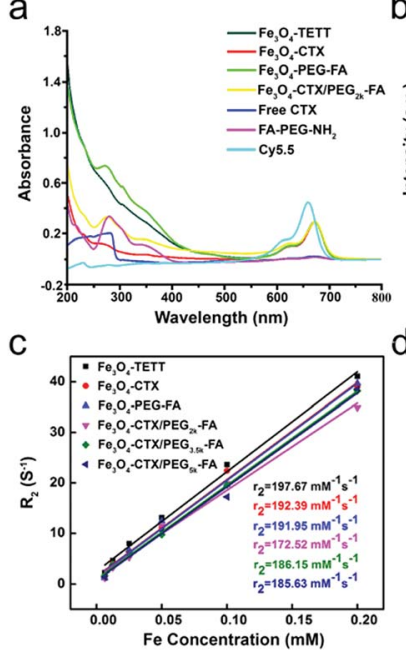

b

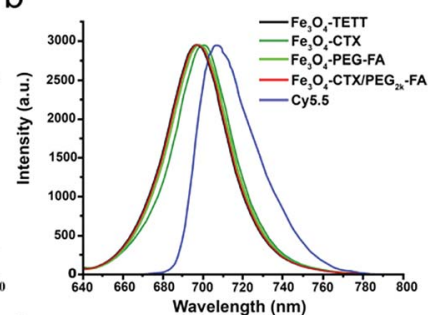

d

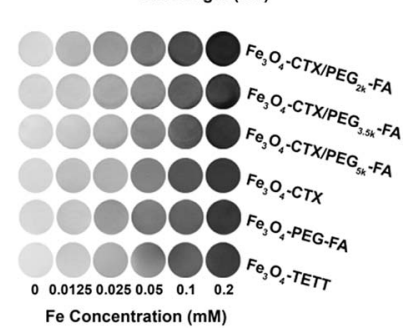

Fig. 2 UV-Vis absorbance (a) and fluorescence emission (b) spectra, $r_{2}$ relaxivities (c), and the corresponding $M R T_{2}$-weighted $M R$ mapping (d) of NPs.

to those reported in other studies and are sufficient for MR $T_{2}$ imaging. This was supported by the corresponding MR $T_{2}$ mapping of NPs dispersed in water, which exhibited a gradual darkening effect with increase of Fe concentration (Fig. 2d).

\subsection{Enhanced cellular uptake of dual-targeting NPs by C6 cells}

Prior to cellular uptake experiment, the cytotoxicity of asprepared non-targeting, single-targeting, and dual-targeting NPs towards C6 cells was first evaluated. It was found that cell viability was $>85 \%$ within tested concentrations regardless of the type of NPs (Fig. S3†), indicating that all NPs have low cytotoxicity in vitro.

The target ability of dual-targeting $\mathrm{Fe}_{3} \mathrm{O}_{4}$ NPs and the effect of different relative lengths of the CTX/PEG-FA dual-target on targeting selectivity were evaluated by flow cytometry in C6 cells. As shown in Fig. 3, C6 cells treated with single-targeting $\mathrm{Fe}_{3} \mathrm{O}_{4}$ NPs with CTX or PEG-FA exhibited a slight increase in fluorescence intensity relative to that treated with non-targeting NPs (Fig. 3a). In contrast, CTX/PEG-FA dual-targeting NPs led to an obvious increase in fluorescence intensity. The enhanced cellular uptake suggested improved selectivity of these NPs towards $\mathrm{C} 6$ cells. More importantly, the cellular uptake of dualtargeting $\mathrm{Fe}_{3} \mathrm{O}_{4}$ NPs varied with the length of PEG conjugated on FA (Fig. 3a), demonstrating that targeting efficiency of dualtargeting NPs toward glioma cells can be modulated by adjusting the relative length of the dual-target.

In addition, receptor blocking experiment was performed to examine the specificity of dual-targeting NPs. In order to block MMP-2 or/and FR, excess CTX, PEG-FA, or CTX/PEG-FA was added to the $\mathrm{C} 6$ cells. When MMP-2 was blocked, a reduced cellular uptake was observed for NPs containing CTX $\left(\mathrm{Fe}_{3} \mathrm{O}_{4}\right.$ CTX and $\mathrm{Fe}_{3} \mathrm{O}_{4}-\mathrm{CTX} / \mathrm{PEG}_{2 \mathrm{k}}-\mathrm{FA}$ ) (Fig. 3b). Similarly, adding excess FA inhibited the binding of FA-containing NPs to FR (Fig. 3c). This thus confirms that both MMP-2 and FR are

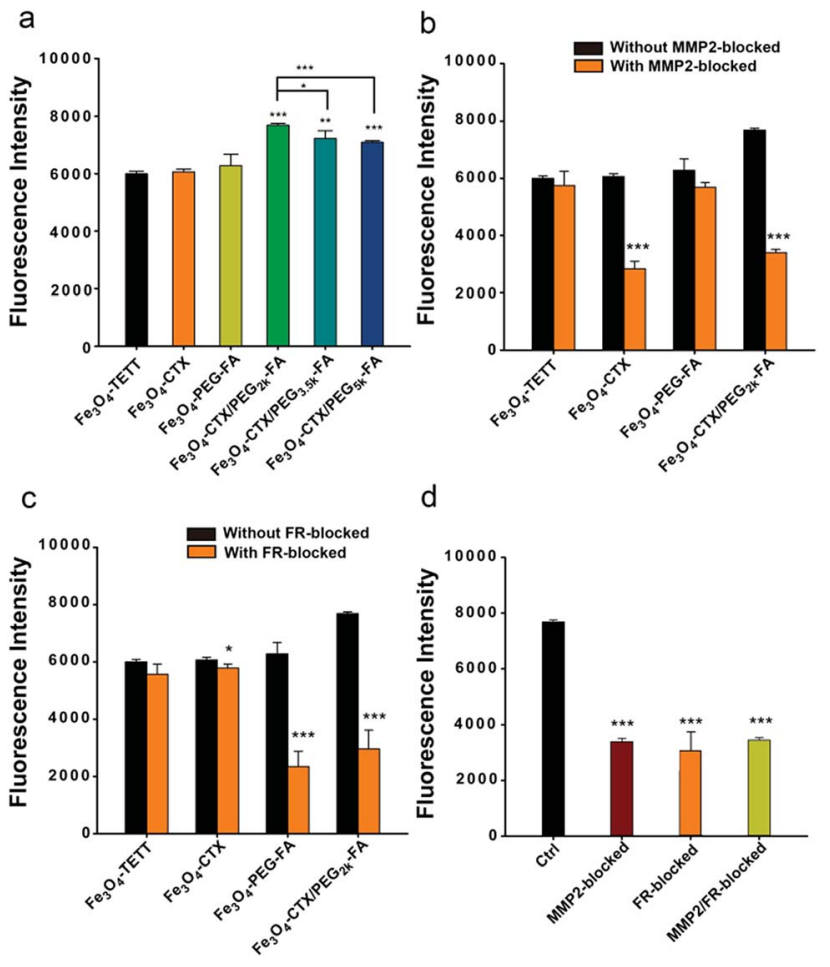

Fig. 3 Fluorescence intensity of non-blocked (a), MMP-2 blocked (b), FR blocked (c), and MMP-2/FR blocked (d) C6 cells incubated with different NPs. Each data represents the mean of three independent experiments and error bars denote standard deviation. *** denotes $P<$ 0.001 , ** denotes $P<0.01$, $*$ denotes $P<0.05$ as determined by Student's t-test.

presented on the surface of C6 cells. Fig. 3d plots the fluorescence intensity of the control (none of receptor was blocked) and receptor-blocked cells (one or both receptors were blocked) treated with dual-targeting NPs. Obviously, cells bearing one or none of the targeted receptors exhibited significant reduced fluorescence intensity in comparison with the control cells bearing both targeted receptors, reflecting the enhanced targeting specificity of dual-target.

\subsection{MR imaging of brain gliomas}

The targeting ability of dual-targeting $\mathrm{Fe}_{3} \mathrm{O}_{4}$ NPs and the effect of the relative length of dual-target on this specificity were further evaluated by in vivo MR imaging of brain glioma-bearing mice. $T_{2}$-weighted $\mathrm{MR}$ images pre- and post-injection these $\mathrm{Fe}_{3} \mathrm{O}_{4}$ NPs were obtained and pseudo-colored in order to highlight the negative (darker) contrast enhancements (Fig. 4). For non-targeting $\mathrm{Fe}_{3} \mathrm{O}_{4} \mathrm{NPs}$, there was no notable change in MR signal intensity following injection. Compared to images of non-targeting $\mathrm{Fe}_{3} \mathrm{O}_{4}$ NPs (gliomas shown as red and yellow in Fig. 4), single-targeting $\mathrm{Fe}_{3} \mathrm{O}_{4}$ NPs showed decreased $T_{2}$ signal intensity in brain gliomas (darker contrast effect; shown as yellow and green in Fig. 4) attributable to the enhanced targeting specificity. The dual-targeting $\mathrm{Fe}_{3} \mathrm{O}_{4}$ NPs, however, exhibited a much greater decrease in signals (shown as greenand blue-color), obviously due to the higher specificity. 


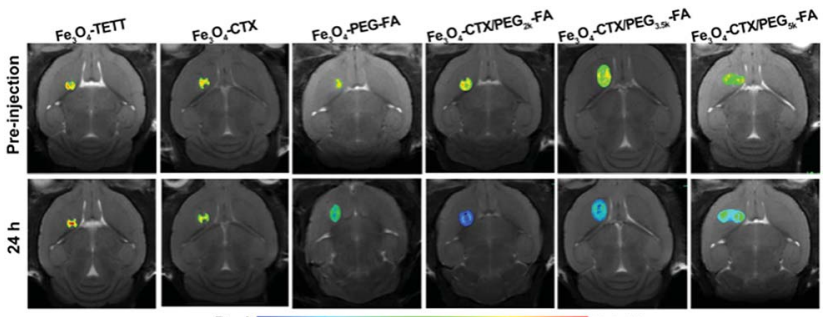

Dark Bright

Fig. 4 Pseudo-colored MR $T_{2}$-weighted images of mice brains harboring gliomas before and after i.v. injection of NPs at a dose of $10 \mathrm{mg}$ Fe per kg.

Moreover, it was clearly evidenced that $T_{2}$ signal intensity decreased with increasing PEG length, probably because longer PEG chains could affect the targeting specificity due to the shielding effect. ${ }^{\mathbf{2 8} 29}$ This further underscores the impact of the relative length on glioma targeting and consequently, the MR contrast effect.

\subsection{In vivo NIR fluorescence imaging}

To further investigate the targeting specificity of dual-targeting $\mathrm{Fe}_{3} \mathrm{O}_{4}$ NPs with different relative length, accumulation of nontargeting, single-targeting, and series of dual-targeting NPs at the glioma site $1 \mathrm{~h}$ post-injection was compared by in vivo NIR imaging (Fig. 5). There was no accumulation of non-targeting NPs in gliomas, whereas slight accumulation of singletargeting NPs was observed. In contrast, dual-targeting NPs exhibited high accumulation in the tumour region as compared to single-targeting NPs, providing additional evidence for their improved specificity towards gliomas. Consistent with the

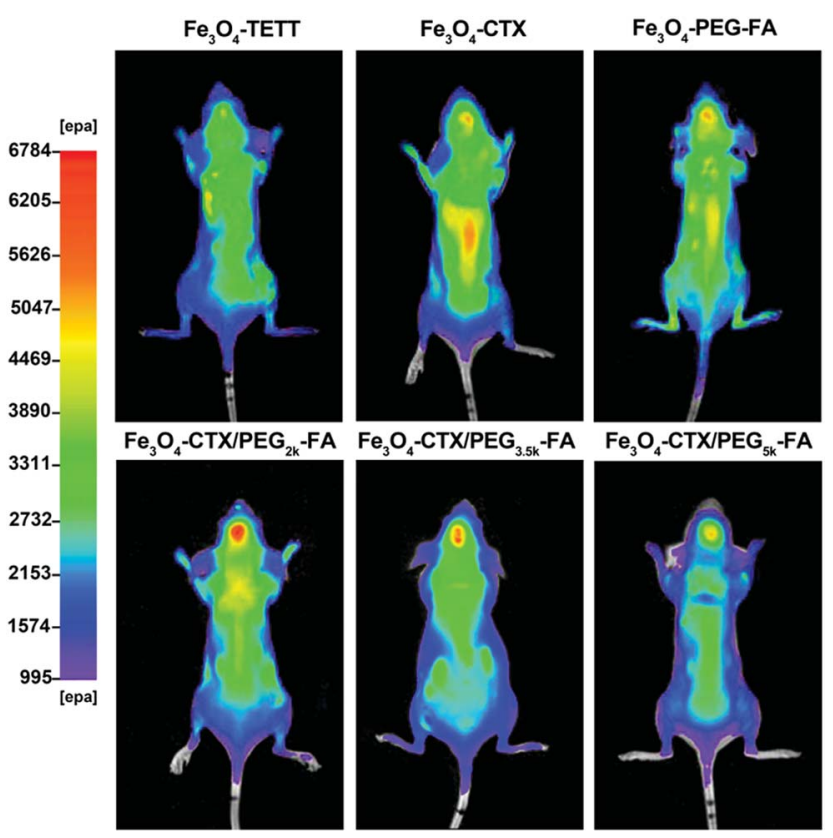

Fig. 5 In vivo NIR fluorescence images of brain glioma-bearing mice after injection of NPs at a dosage of $10 \mathrm{mg}$ Fe per $\mathrm{kg}$. results of in vivo $\mathrm{MR}$ imaging, accumulation of the dualtargeting NPs varied with the relative length of dual-target. Therefore, the in vivo MRI and NIR imaging results confirm that the targeting specificity of dual-targeting $\mathrm{Fe}_{3} \mathrm{O}_{4}$ NPs could be affected by the relative length of dual-target.

\subsection{Confocal laser scanning microscopy analysis}

Furthermore, the location of NPs in the glioma-bearing brain was examined by confocal microscopic imaging of brain slices harboring gliomas. Non-targeting NPs was found surrounding the glioma, showing weak red fluorescence signal (Fig. 6a), single-targeting NPs $\left(\mathrm{Fe}_{3} \mathrm{O}_{4}\right.$-PEG-FA and $\left.\mathrm{Fe}_{3} \mathrm{O}_{4}-\mathrm{CTX}\right)$ emitted similar fluorescence intensity but were mostly localized within tumors due to the specific binding of the single-target to the receptor. As expected, dual-targeting $\mathrm{Fe}_{3} \mathrm{O}_{4}$ NPs, especially
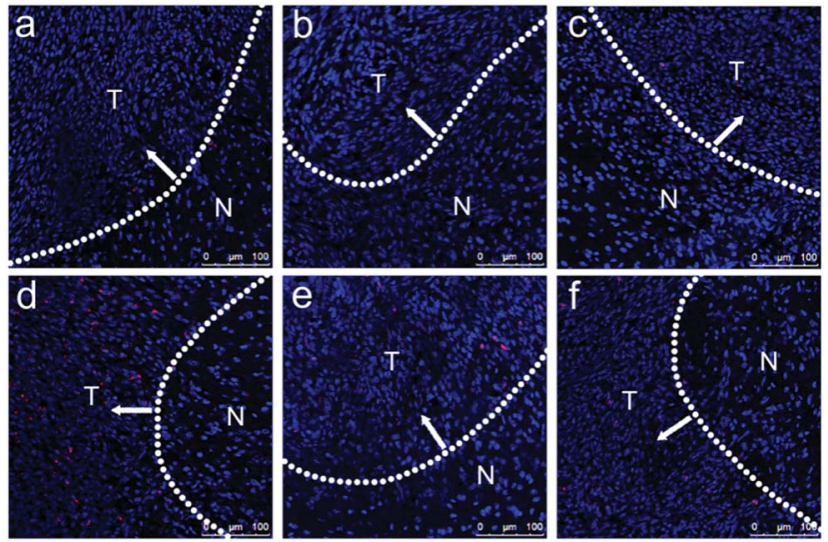

Fig. 6 Confocal microscopic imaging of brain slices harboring gliomas treated with non-targeting (a), $\mathrm{Fe}_{3} \mathrm{O}_{4}-\mathrm{CTX}$ (b), $\mathrm{Fe}_{3} \mathrm{O}_{4}-\mathrm{PEG}-\mathrm{FA}$ (c), $\mathrm{Fe}_{3} \mathrm{O}_{4}-\mathrm{CTX} / \mathrm{PEG} \mathrm{k}_{2 \mathrm{k}}-\mathrm{FA}$ (d), $\mathrm{Fe}_{3} \mathrm{O}_{4}-\mathrm{CTX} / \mathrm{PEG} \mathrm{G}_{3.5 \mathrm{k}}-\mathrm{FA}$ (e), $\mathrm{Fe}_{3} \mathrm{O}_{4}-$ CTX/PEG ${ }_{5 k}-F A$ (f) NPs. Blue: cell nuclei stained with DAPI. Red: Cy5.5labeled NPs. Scale bar $=100 \mu \mathrm{m}$.

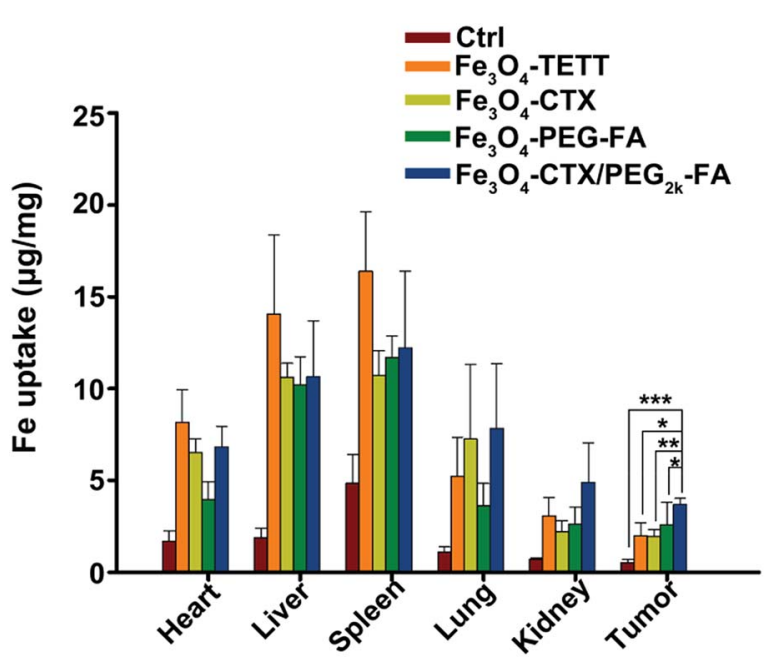

Fig. 7 Biodistribution of NPs in brain glioma-bearing mice. The data represent the mean \pm S.D. $(n=3)$. *** denotes $P<0.001$, ** denotes $P$ $<0.01$ * denotes $P<0.05$ as determined by Student's $t$-test. 
the $\mathrm{Fe}_{3} \mathrm{O}_{4}-\mathrm{CTX} / \mathrm{PEG}_{2 \mathrm{k}}-\mathrm{FA}$ NPs, exhibited greater fluorescence intensity within gliomas owing to improved targeting specificity.

\subsection{Biodistribution and in vitro toxicity}

Additionally, the biodistribution of NPs in glioma-bearing mice $24 \mathrm{~h}$ after injection was evaluated by measuring the Fe content of major organs. As shown in Fig. 7, the NPs were mainly distributed in the liver and spleen; however, dual-targeting NPs showed higher accumulation in the brain than that of nontargeting and single-targeting NPs $(P<0.001)$, confirming their enhanced targeting selectivity for gliomas.

\section{Conclusions}

In sum, we synthesized Cy5.5-labeled $\mathrm{Fe}_{3} \mathrm{O}_{4}$ NPs with CTX/PEGFA dual-target of varied relative lengths. The in vitro cellular uptake and in vivo MR/NIR imaging results indicated that relative length of dual-target plays a role in the brain glioma targeting as the targeting ability of dual-targeting $\mathrm{Fe}_{3} \mathrm{O}_{4}$ NPs towards brain glioma could be affected by adjusting the relative length of dual-target. Therefore, the relative length of dualtarget should be taken into account in future design of dualtargeting NPs.

\section{Acknowledgements}

The authors gratefully acknowledge the financial support from the Natural Science Foundation of China (81271639), the Key Project from Beijing Commission of Education (KZ201610025022), National Key Technology Research and Development Program of the Ministry of Science and Technology of China (No. 2014BAI04B01), and the Beijing Natural Science Foundation (7162023).

\section{References}

1 M. Mahmoudi, S. Sant, B. Wang, S. Laurent and T. Sen, Adv. Drug Delivery Rev., 2011, 63, 24-46.

2 N. Lee and T. Hyeon, Chem. Soc. Rev., 2011, 41, 2575-2589.

3 B. H. Kim, N. Lee, H. Kim, K. An, Y. I. Park, Y. Choi, K. Shin, Y. Lee, S. G. Kwon and H. B. Na, J. Am. Chem. Soc., 2011, 133, 12624-12631.

4 J. Huang, X. Zhong, L. Wang, L. Yang and H. Mao, Theranostics, 2012, 2, 86-102.

5 L. Li, W. Jiang, K. Luo, H. Song, F. Lan, Y. Wu and Z. Gu, Theranostics, 2013, 3, 595-615.

6 F. Chen and M. Zhang, J. Mater. Chem., 2009, 19, 6258.

7 H. Xie, Y. Zhu, W. Jiang, Q. Zhou, H. Yang, N. Gu, Y. Zhang, H. Xu, H. Xu and X. Yang, Biomaterials, 2010, 32, 495-502.
8 Z. Zhelev, R. Bakalova, I. Aoki, K. Matsumoto, V. Gadjeva, K. Anzai and I. Kanno, Mol. Pharmaceutics, 2009, 6, 504-512. 9 H. L. Liu, M. Y. Hua, H. W. Yang, C. Y. Huang, P. C. Chu, J. S. Wu, I. C. Tseng, J. J. Wang, T. C. Yen and P. Y. Chen, Proc. Natl. Acad. Sci. U. S. A., 2010, 107, 15205-15210.

10 M. Abdolahi, D. Shahbazi-Gahrouei, S. Laurent, C. Sermeus, F. Firozian, B. J. Allen, S. Boutry and R. N. Muller, Contrast Media Mol. Imaging, 2013, 8, 175.

11 X. Gao, Y. Cui, R. M. Levenson, L. W. Chung and S. Nie, Nat. Biotechnol., 2004, 22, 969-976.

12 J. Shi, L. Wang, Y. S. Kim, S. Zhai, Z. Liu, X. Chen and S. Liu, J. Med. Chem., 2008, 51, 7980-7990.

13 M. Kumar, G. Singh, V. Arora, S. Mewar, U. Sharma, N. R. Jagannathan, S. Sapra, A. K. Dinda, S. Kharbanda and H. Singh, Int. J. Nanomed., 2012, 7, 3503-3516.

14 Y. Bae and K. Kataoka, Adv. Drug Delivery Rev., 2009, 61, 768784.

15 R. K. Dutta and S. Sahu, Eur. J. Pharm. Biopharm., 2012, 82, 58-65.

16 J. Zhang, N. Chen, H. Wang, W. Gu, K. Liu, P. Ai, C. Yan and L. Ye, J. Colloid Interface Sci., 2016, 469, 86-92.

17 C. Zhan, B. Gu, C. Xie, J. Li, Y. Liu and W. Lu, J. Controlled Release, 2010, 143, 136-142.

18 K. M. Wood, G. M. Stone and N. A. Peppas, Biomacromolecules, 2008, 9, 1293-1298.

19 E. Song, P. Zhu, S. K. Lee, D. Chowdhury, S. Kussman, D. M. Dykxhoorn, Y. Feng, D. Palliser, D. B. Weiner and P. Shankar, Nat. Biotechnol., 2005, 23, 709-717.

20 A. Kippert, D. Fitzner, J. Helenius and M. Simons, BMC Cell Biol., 2009, 10, 1-11.

21 A. E. Nel, L. Mädler, D. Velegol, T. Xia, E. M. V. Hoek, P. Somasundaran, F. Klaessig, V. Castranova and M. Thompson, Nat. Mater., 2009, 8, 543-557.

22 C. Zhu and T. E. Williams, Biophys. J., 2000, 79, 1850-1857.

23 D. D. Gibbs, D. S. Theti, N. Wood, M. Green, F. Raynaud, M. Valenti, M. D. Forster, F. Mitchell, V. Bavetsias and E. Henderson, Cancer Res., 2005, 65, 11721-11728.

24 O. Veiseh, J. W. Gunn, F. M. Kievit, C. Sun, C. Fang, J. S. H. Lee and M. Zhang, Small, 2008, 5, 256-264.

25 A. H. Kaye, G. Morstyn, I. Gardner and K. Pyke, Cancer Res., 1986, 46, 1367-1373.

26 H. Zhu, J. Tao, W. Wang, Y. Zhou, P. Li, Z. Li, K. Yan, S. Wu, K. W. Yeung and Z. Xu, Biomaterials, 2013, 34, 2296-2306.

27 Z. Luz and S. Meiboom, J. Chem. Phys., 1964, 40, 2686-2692. 28 G. Villaverde, A. Baeza, G. J. Melen, A. Alfranca, M. Ramírez and M. Vallet, J. Mater. Chem. B, 2015, 3, 4831-4842.

29 Q. He, J. Zhang, J. Shi, Z. Zhu, L. Zhang, W. Bu, L. Guo and Y. Chen, Biomaterials, 2010, 31, 1085-1092. 